\title{
LSPIV implementation for environmental flow in various laboratory and field cases
}

\author{
Sameh A. Kantoush ${ }^{\text {a,*}}$, Anton J. Schleiss ${ }^{\text {b }}$, Tetsuya Sumi ${ }^{\text {c }}$, Mitsuhiro Murasaki ${ }^{\text {d }}$ \\ ${ }^{a}$ Civil Engineering Department, Faculty of Engineering and Material Science, The German University in Cairo - GUC, New Cairo City, Main Entrance \\ of Al-Tagamoa Al-Khames, Cairo, Egypt \\ ${ }^{\mathrm{b}}$ Laboratory of Hydraulic Constructions (LCH), Ecole Polytechnique Fédérale de Lausanne (EPFL), Station 18, 1015 Lausanne, Switzerland \\ ${ }^{\mathrm{c}}$ Water Resources Research Centre, Disaster Prevention Research Institute, Kyoto University, Gokasho, Uji, Kyoto 611-0011, Japan \\ d Oyo Corporation, Chiyoda-ku Kandaiwamo to cho1, Shimizu BLD. 1, Tokyo 101-0033, Japan
}

Received 29 June 2010; accepted 10 July 2011

\begin{abstract}
Large-Scale Particle Image Velocimetry (LSPIV) is an extension of a quantitative imaging technique to measure water surface velocities using simple and inexpensive equipment. This paper describes the implementation of imaged-based LSPIV in eight different environmental flow and hydraulic engineering applications for the investigation of complex configurations with and without sediment transport (bed and suspended loads). These applications include the investigation of sedimentation in shallow reservoirs, run-of-river hydropower plants, side weirs used to control bank overflow, flow fields in different spillway configurations with and without Piano Key Weir (PKW), oil spills with flexible and rigid barriers, groin fields, river confluence, and sediment flushing in reservoirs. The paper summarises some special problems encountered in such study cases. The selection and adjustments of the parameters to solve them properly were examined. The potential of LSPIV to measure surface flow velocities in the context of river and dam engineering projects is shown. Despite significant variations of natural and artificial illuminations and seeding tracers in the laboratory, field, wind, and water surface elevation, LSPIV was applied successfully to obtain velocity measurements. LSPIV has proven to be a reliable, flexible, and inexpensive flow diagnostic tool that can be employed successfully in many engineering applications.

(c) 2011 International Association for Hydro-environment Engineering and Research, Asia Pacific Division. Published by Elsevier B.V. All rights reserved.
\end{abstract}

Keywords: LSPIV; Laboratory measurements; Field applications; Dam engineering and reservoirs; CCTV; Optical flow (FX-8100)

\section{Introduction}

The laboratory and field monitoring of environmental flows is essential in projects involving the investigation of flow patterns, sediment deposition, bank erosion, and environmental impact. Flow monitoring is also an important technology in the design and planning of hydraulic structures with regions of flow separation in natural environments and sediment management techniques. New technologies have been developed for

\footnotetext{
* Corresponding author. Tel.: +20 2 75899908x1299; fax: +20227582125.

E-mail addresses: sameh.kantoush@guc.edu.eg, Kantoush@yahoo.com (S.A. Kantoush).
}

discharge and surface velocity measurements due to concerns about flow conditions, costs, accuracy, inaccessible locations, measuring time and the safety of conventional methods. One emerging technology is large-scale particle image velocimetry (LSPIV), which has several advantages over conventional measurement techniques; namely, LSPIV is safer, non-intrusive and provides continuous measurements (Muste et al., 2008).

The standard PIV method has been applied to velocity measurements at larger scales, commonly called large-scale particle image velocimetry (LSPIV) (Aya et al., 1995; Fujita et al., 1998). In contrast to the tracking of isolated particles, LSPIV covers a large area and allows for the detection of stagnation areas and vortices. Knowledge of surface velocities has 
proven to be useful in many experimental situations, including the investigation of LSPIV sensitivity analysis (Meselhe et al., 2004), observation of floating objects such as ice sheets and their impact on flow patterns (Ettema et al., 1997) and measurement of large coherent structures in shallow reservoirs of different geometries (Kantoush and Schleiss, 2009a). Furthermore, several researchers (e.g., Weitbrecht et al., 2002; Meselhe et al., 2004; Kantoush and Schleiss, 2009b) have studied shallow flows under large-scale laboratory conditions. LSPIV has been extensively applied to various laboratory models for bridge scour (e.g., Morales et al., 2008) and for the approach flow of power plant spillways (e.g., Bieri et al., 2009; De Cesare et al., 2010).

The implementation of LSPIV is now popular in the river engineering community, and $2 \mathrm{D}$ vector fields of time-averaged surface velocities are typically measured for environmental flows; examples of applications include measuring the distribution of surface velocities in a large physical model of Lake Ogallala, a reservoir in central Nebraska (Admiraal et al., 2004). The use of the LSPIV technique in field applications is now widespread after the pioneering work of Fujita and Komura (1994) and Fujita et al. (1998) and has been significantly improved (Fujita and Tsubaki, 2002; Fujita and Aya, 2000). Recently, in Japan, the LSPIV technique was successfully applied to monitor the flow patterns during sediment bypassing from Lake Miwa to downstream areas below Miwa Dam (Kantoush et al., 2011) and also during sediment replenishment below Murou Dam (Kantoush and Sumi, 2010). LSPIV has also been implemented to measure the discharges in the Yodo River (Fujita et al., 1998), Kino River (Fujita and Aya, 2000) and Uono River (Fujita and Tsubaki, 2002) in Japan; the Iowa River (Creutin et al., 2003) in the USA; the Arc River (Jodeau et al., 2008) and Ardèche River (Le Coz et al., 2010) in France; and River Blackwater (Sun et al., 2010) in the UK.

In the present study, seven laboratory and one-field cases for different applications were investigated using the LSPIV technique. The goal of this study was to describe and analyse the physical processes involved in flow structure formation in the implemented cases, to encourage LSPIV use and to improve its capabilities for collecting field and experimental data that are needed to better understand complex environmental flow processes and interactions under normal and extreme conditions.

\section{Comparison of LSPIV parameters for different case studies}

The LSPIV system used in this study for laboratory model cases was composed of six elements: a camera, tracer particles, a tracer distributer, an illumination system, a computer for data acquisition and analysis, and software. Depending on the flow velocity, either an SMX-150 or SUMIX-155M camera was used to record images of the flow at a suitable rate with adequate image resolution. However, for the field application case, a CCTV (CIT-7300) camera from Mitsubishi was selected and connected to a computer for data recording. In the field case, naturally occurring tracers and lighting were used, as summarised in Table 1. An overview and comparison of LSPIV parameters for all laboratory and field cases are given in Table 1.
The sampling frequency of the recorded images has a significant influence on the accuracy of the LSPIV velocity estimates. For most laboratory models, a CMOS SUMIX$155 \mathrm{M}$ camera with a USB2.0 interface and a gray-scale resolution of 12 bits was used to capture images of tracer particles on the surface of the model. The camera was an active-imaging, 1.3 -megapixel $(1280 \times 1024)$ CMOS camera that can record up to 33 frames per second. Nevertheless, for the oil spill barrier case, a 6.6-megapixel $(2206 \times 3000)$ CMOS sensor, SMX-150 camera with a USB2.0 interface and a high-resolution megapixel lens was used (Table 1). A wideangle lens was used with the SUMIX-155M digital camera to capture large measurement planes. Consequently, lens calibrations were performed using the PTLens and FlowManager software. Details of this software can be found in Kantoush and Schleiss (2009a).

Determining which seed particle to use for PIV is very important, as shown in Table 1. The seed particles must be large enough to scatter sufficient light for imaging but small enough to track accurately the fluid flow. In addition, the number of particles in the seeding volume must be determined such that the spatial resolution of particles provides images that are suitable for processing. The particles have to fit different requirements to be applicable. In the laboratory model cases of surface velocity measurements, the tracer particles have to float at the water surface, so the material has to be somewhat lighter than water, except in the oil spill barrier case. In most of the laboratory cases, the flow was seeded with white, floating, cylindrical polypropylene particles with an average diameter of $3.4 \mathrm{~mm}$ and a density of $960 \mathrm{~kg} / \mathrm{m}^{3}$, as shown in Table 1 . To minimise agglomeration effects, they were coated with paint. A homogeneous distribution of particles within the measuring field is important to obtain good results in terms of a closed velocity vector field. A tracer distributer that is able to seed the water surface homogeneously with particles at a rate that depends on the ambient flow velocity has to be developed. However, for a flushing flow (the field case), the flow velocity is high, and apparent patterns at the free surface generated by large turbulences can be detected as boils. Moreover, different water colours were generated during sediment flushing (Table 1).

The illumination component proved to be the most crucial for obtaining high-quality data. Natural lighting was used for field cases, and either the laboratory's halogen lamps or artificial lighting was used for laboratory cases. The spots must be placed around or on top of the camera to obtain a homogeneous light intensity distribution over the entire area; otherwise, the reflections and shadows will show different characteristics on either side. Several illumination arrangements were tested to obtain good-quality recordings. Four lamps were positioned face-to-face on both longitudinal sides of the flow field. For all eight cases, a calibration task requires checking the accuracy of the LSPIV system. The accuracy of the LSPIV method was tested using different methods, such as a micro-propeller, ultrasonic Doppler velocity profiler (UVP), optical flow system (FX-8100), and numerical simulation. Table 1 shows the calibration method and accuracy for all field and laboratory case studies. 
Table 1

Overview of LSPIV settings and parameters.

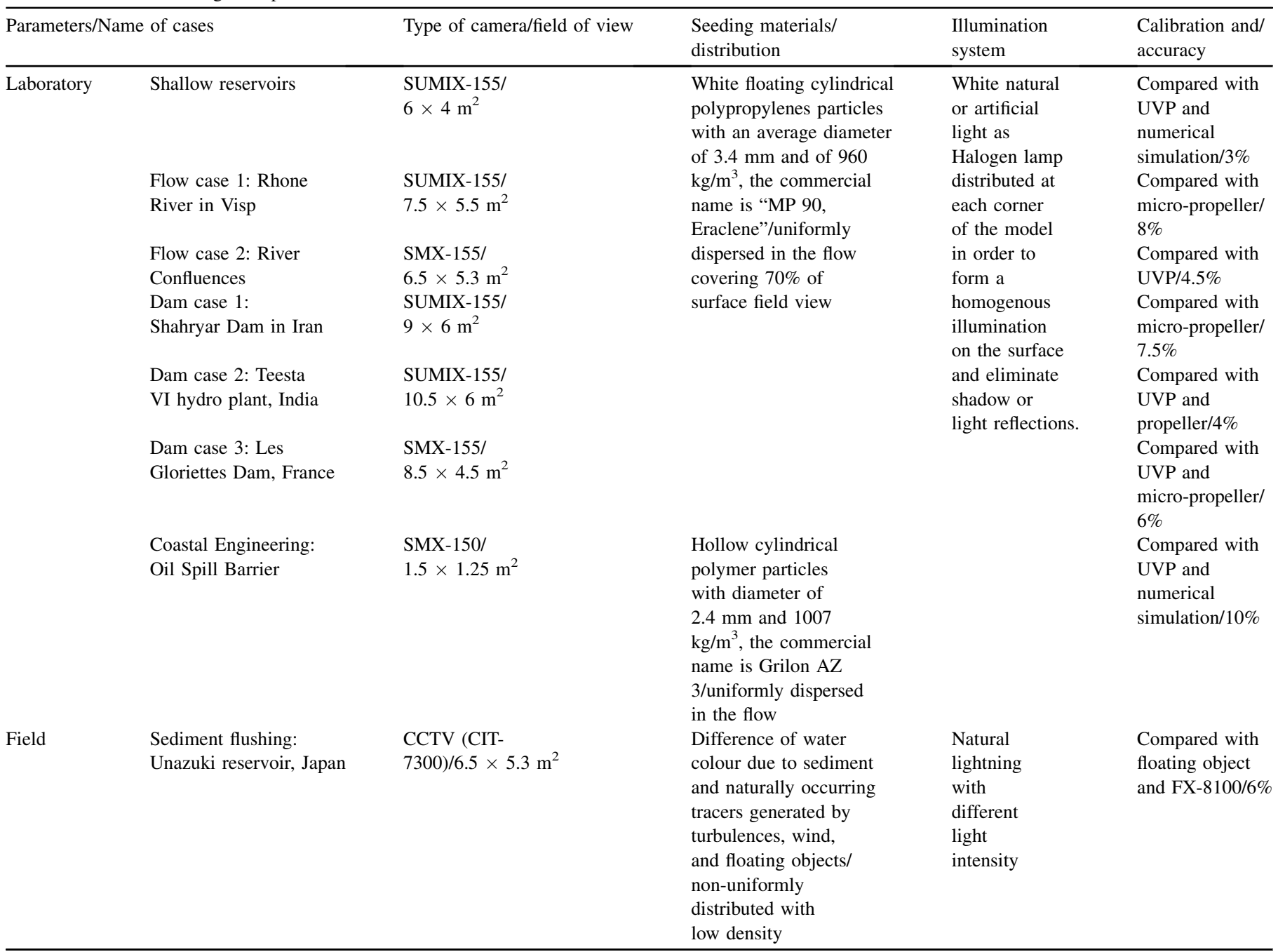

\section{Laboratory experiments}

\subsection{LSPIV system}

The Laboratory of Hydraulic Constructions ( $\mathrm{LCH}$ ) of the Swiss Federal Institute of Technology (EPFL) in Switzerland has at its disposal the complete equipment set for conducting LSPIV measurements that is commonly used in the context of fundamental and applied research projects. Moreover, all of the presented LSPIV applications of laboratory cases were measured by the same LSPIV system except for the oil spill barrier case (Table 1). A digital camera connected to the computer was used to record the images. The camera was fixed perpendicularly above the analysed zone, covering the whole area of interest.

\subsection{Flow patterns in shallow reservoirs}

\subsubsection{Purpose of the study}

In the framework of a research project, the influence of the large shallow basin geometry on the flow characteristics is presented. The present article describes a simple method developed using the advantages of PIV. Moreover, measurements are presented from cases where the system was applied to a laboratory problem to analyse surface flow in shallow basins of various shapes and to investigate the use of LSPIV in measuring the time dynamics of the flow. In addition to the determination of mean flow conditions and turbulent flow characteristics, this method makes it possible to track twodimensional, large, coherent structures, which are the dominant flow phenomena in many shallow flow applications.

\subsubsection{Measurement methods}

To gain insight into the physical processes underlying the complex flow patterns, a reference basin geometry with a width of $B=4.0 \mathrm{~m}$ and a length of $\mathrm{L}=6.0 \mathrm{~m}$ was used. The non-intrusive LSPIV was implemented during tests with sediment transport in cases where the use of other measurement techniques was sometimes not possible.

\subsubsection{Accuracy of the measuring system}

The accuracy was tested using two simple test cases. First, the fully developed laminar flow in the straight approach 
channel with dimensions of $8.0 \mathrm{~m}$ in length (the entire length of the installation) and $0.25 \mathrm{~m}$ in width was measured. A comparison of the average velocity profile in the main flow direction obtained with LSPIV and numerical simulations at the middle of a straight channel is shown in Fig. 1a. The second test of the accuracy of the LSPIV measurements was performed in a rectangular reservoir of $5.0 \mathrm{~m}$ in length and $3.0 \mathrm{~m}$ in width by comparing them with UVP measurements and the results of numerical simulations. Fig. $1 \mathrm{~b}$ compares the computed and measured values of axial velocity at the centreline of the basin. Velocity distributions determined by UVP and LSPIV are approximately the same in the approach channel. More details on comparing numerical simulations and measured data can be found in Kantoush et al. (2008).

\subsubsection{Results}

In Fig. 2a and b, the flow patterns are shown by the average velocity vectors for two different geometries. The effect of the geometry on the flow field and the separation zone on both sides of reservoir is of particular interest. In Fig. 2a, the surface flow pattern has an asymmetric behaviour, leading to a larger gyre size in the right upstream corner than in the left corner. The main gyre size is in accordance with the two corner gyres. The stable asymmetric pattern, with a larger and smaller recirculation zone at the right and left corners, respectively, can be explained by a Coanda effect, in which any perturbation of the flow field, pushing the main flow to one side of the basin gives rise to larger velocities at the left side along the jet. Thus, the asymmetry will naturally tend to be accentuated by the Coanda effect. Due to a reduced basin length (Fig. 2b), the flow stabilises with a stable symmetrical pattern, and four gyres exist in the basin. The four gyres interact with the jet, which has some tendency to meander.

The evolution of the flow patterns for a rectangular reservoir was studied to emphasise the effectiveness of LSPIV for measuring the time dynamics of a flow, as shown in Fig. 3 . Velocity vectors at various times are shown in Fig. $3 \mathrm{a}$ and $\mathrm{b}$ to track the horizontal trajectories of the vortex pairs as a function of time. LSPIV was successfully able to track the time evolution of flow patterns that allows for the determination of the evolution of the gyres and measurement of the time dynamics of the flow. Because the gyre dipole expelled from the jet produces a localised stream-wise jet along the centreline, an easy way to track the location of the gyre dipole is to track the local maximum of the velocity on the jet centreline.

\subsection{River engineering applications}

River engineering is often linked to dynamic evolutions in flow and/or channel geometry. Physical models are used to analyse several characteristics, such as water level elevation, boundaries of flooded areas, cross-sectional flow velocities, discharge distribution and surface flow velocities (Müller et al., 2002).

b

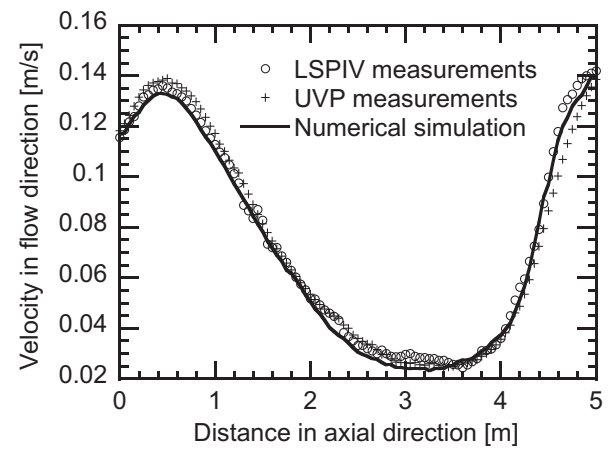

Fig. 1. Comparison of LSPIV, UVP, and numerical simulation velocities for calibration task. (a) Cross section at the middle of straight channel (b) Along the centreline of the reservoir.
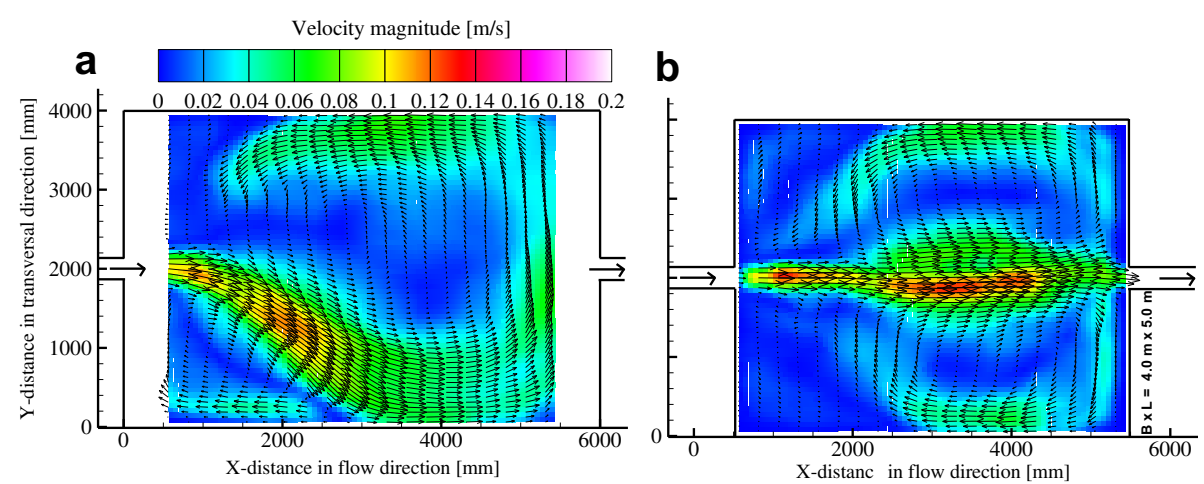

Fig. 2. Average flow pattern in the shallow basin with velocity vectors for two different geometries. 


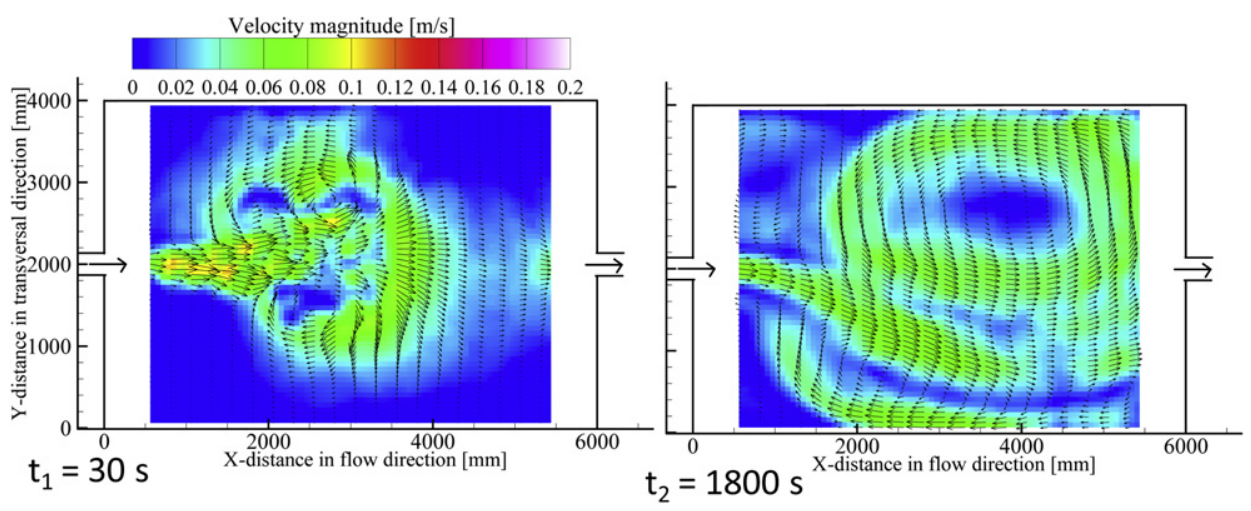

Fig. 3. Time dynamics of flow pattern evolution in shallow reservoir.

\subsection{Flow case 1: Rhone River in Visp}

\subsubsection{Purpose of the study}

The case study, conducted in 2006 at the LCH (Bieri et al., 2009), concerns a side weir used to control overflow in cases of large flood events. The side weir lies upstream of a new river widening of the Rhone River in Visp (Switzerland). The LSPIV tests were performed to examine and to increase the performance of the numerically pre-designed side weir. In addition, surface flow fields at several still-water sections and side river confluences were studied. The surface flow measurements were coupled with mobile sand and gravel bed morphodynamic observations that justified the non-intrusive measurement of LSPIV.

\subsubsection{Experimental problems and solutions}

One of the important problems in the laboratory is choosing the type of seed particle based on characteristics such as colour (particles should have sufficient contrast to the model background), surface distribution, and coalescence. The seed particles must be large enough to scatter sufficient light for imaging but small enough to accurately track the fluid flow. In addition, the number of particles in the seeding volume must be determined such that the spatial resolution of particles provides images suitable for processing. The particles have to fit different requirements to be applicable. In the present case, the flow was seeded with white floating cylindrical polypropylene particles, and a black model bottom was needed. To minimise agglomeration effects, particles were coated with paint. At the beginning of the test, the particles were spread manually over the entire basin surface. Then, a manual continuous distribution at the whole model cross section was located near the water surface to protect surface waves from falling particles.

\subsubsection{Results}

The surface flow measurements were conducted on several sections of the physical model for the 100-year return period flood and for the so-called extreme flood. The measurement areas were chosen for the LSPIV experiments among two other zones that exhibited a special hydraulic behaviour (see Fig. 4a). The photograph in Fig. 4b shows the arrangement and the designed location of the groyne before the widening of Balschiederbach. Zone 1 contains the confluence of the Balschiederbach and the Rhone River. The lateral in flow on the right-hand side $\left(35 \mathrm{~m}^{3} / \mathrm{s}\right)$ is located at the end of a contracted reach of the Rhone River $\left(1000 \mathrm{~m}^{3} / \mathrm{s}\right)$. Zone 2 shows the area downstream of the side weir, which was not operating during the 100-year flood and is characterised by a number of groynes (Fig. 4b) implemented laterally on the left-hand side.

The flow field of zone 1 (see Fig. 5 on the left) reveals the effect of the confluence of the Baltschiederbach and the Rhone River. The lateral in flow leads to a retention in the immediate upstream part of the main river and therefore to sediment deposition. This process is localised in the middle of the river, which results in a lateral flow separation on the right- and lefthand sides of the sediment accumulation. Interesting effects of lateral in flow at the mouth of the Baltschiederbach, such as the concentration of in flow to the right of the Rhone River and the increase of velocities up to cross-section P 47.1, can be

a
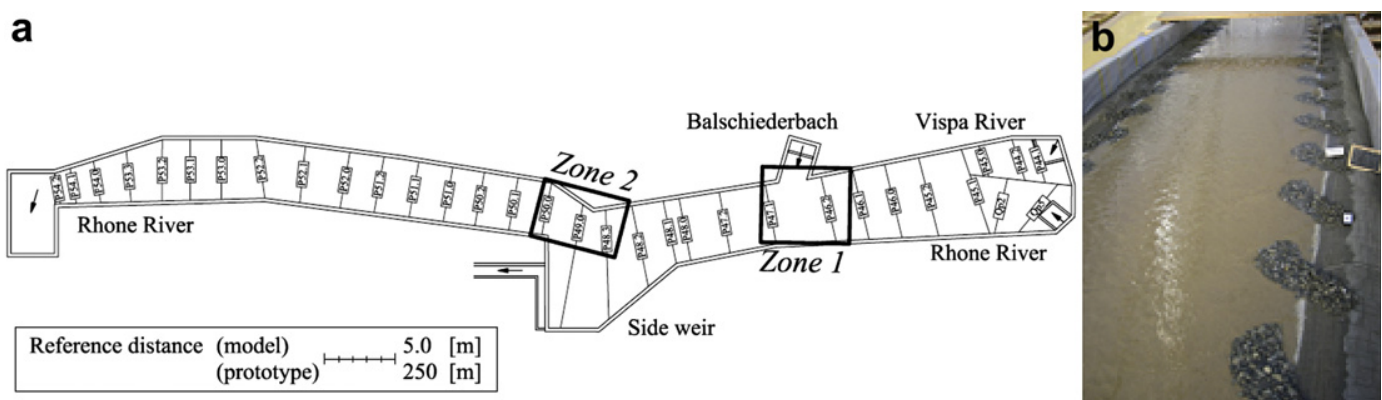

Fig. 4. (a) Experimental set-up of the Rhone River at Visp, (b) Arrangement of groyne locations before the widening of Balschiederbach, downstream looking. 

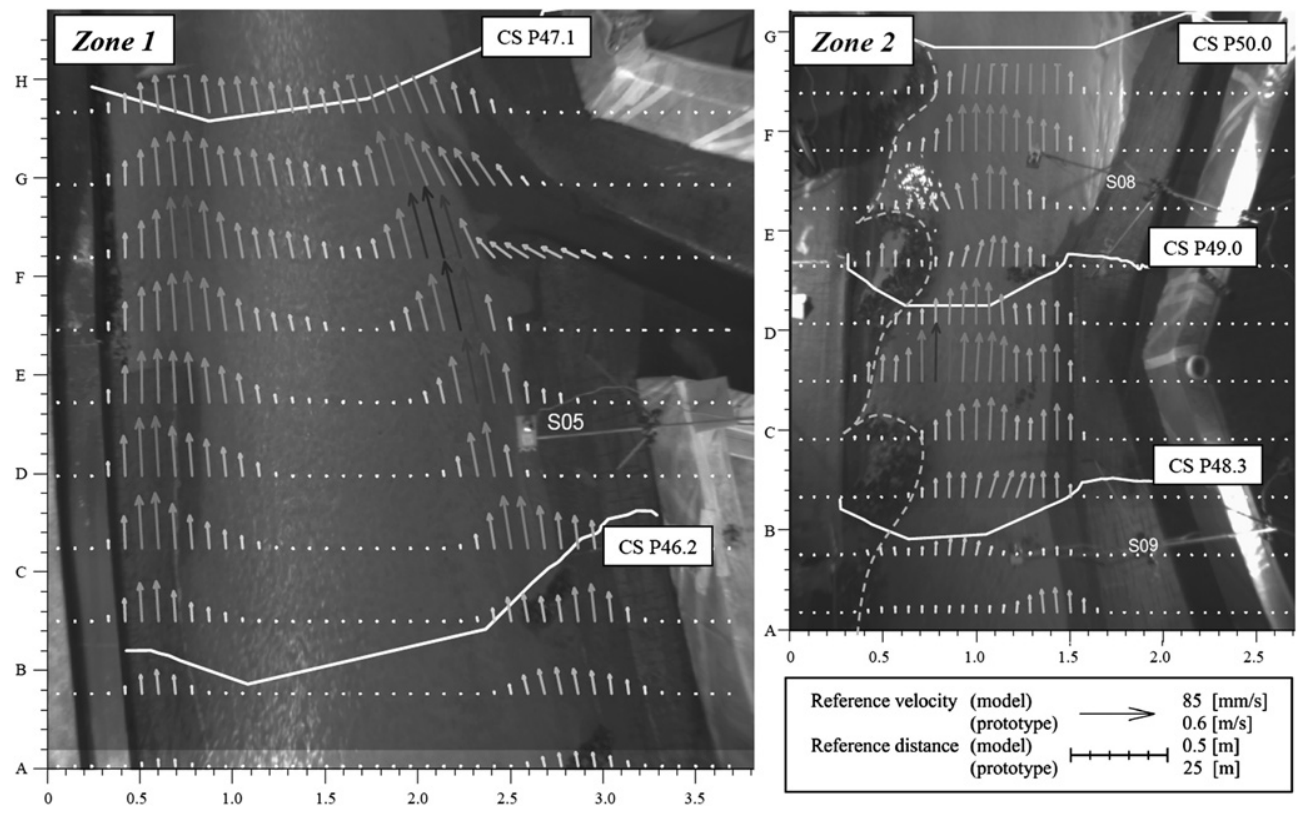

Fig. 5. Upstream view of surface flow of zone 1 (left), zone 2 (right) for 100-years flood.

detected by the measurements. The LSPIV measurements in zone 2 (see Fig. 5 on the right) reveal the impact of the contraction due to the laterally implemented groynes.

\subsection{Flow case 2: river confluences}

\subsubsection{Purpose of the study}

The aim of this study was to obtain a better understanding of the morphological development of alpine river confluences, where special attention was given to the widening of the tributary channel and its influence on bed morphology evolution. The objective of this section is to present the results of the LSPIV application performed for the reference configuration and one tributary widening for one discharge ratio.

\subsubsection{Measurement methods}

Laboratory experiments at LCH (Leite Ribeiro et al., 2008) were performed in a confluence, which is adjustable to enable the testing of several configurations. The main channel is $8.5 \mathrm{~m}$ long, $0.50 \mathrm{~m}$ wide and $0.80 \mathrm{~m}$ deep. A second channel (tributary), which is $5 \mathrm{~m}$ long, $0.50 \mathrm{~m}$ wide and $0.50 \mathrm{~m}$ deep, is connected at an angle of $90^{\circ}$ at a location $3.60 \mathrm{~m}$ downstream of the inlet of the main channel (Fig. 6a). The tributary channel has the possibility of being widened in its downstream area. Poorlysorted sediments were used for the bed constitution and the solid discharge and were composed of a mixture of sand $(0-4 \mathrm{~mm}$; $80 \%)$ and gravel $(4-8 \mathrm{~mm} ; 20 \%)$.

\subsubsection{Experimental problems and solutions}

One of the problems in the present measurement system is the presence of shadows and inhomogeneous distributions of light on the flow surfaces. Several preliminary tests were conducted to cope with the complexity of bed load sediment transport and to achieve proper surface flow illumination. Two different sources of illumination, halogen spots and ultraviolet (UV) lights, were investigated to find the optimum light type

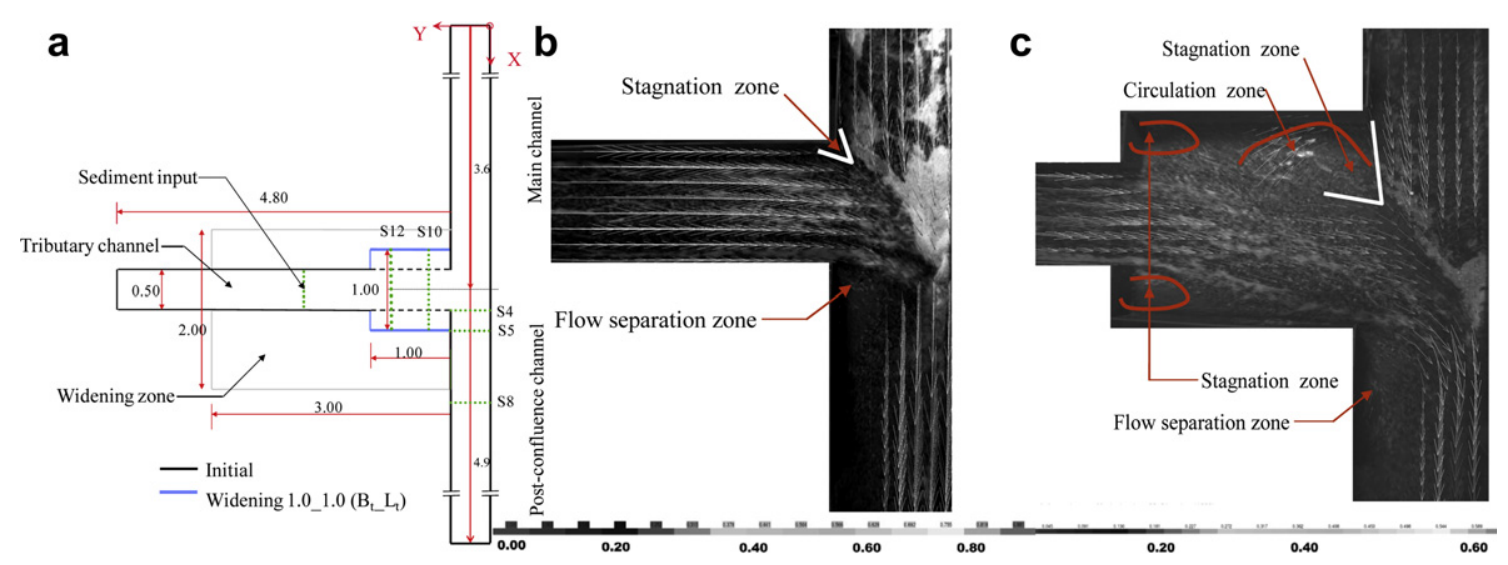

Fig. 6. (a) Experimental installation at LCH (Leite Ribeiro et al., 2008). Average surface flow velocities at the confluence zone for (b) reference configuration and (c) widened configuration. 
and location. However, UV lights were not suitable because the camera was not able to capture the UV light. Therefore, three halogen lamps were positioned on both longitudinal sides of the flumes at various distances from the model to record reflections on the surface. It was possible to position the lamps at variable heights and angles (halogen lamps pointed upward and downward) from the water surfaces.

\subsubsection{Results}

The prediction of average flow conditions at the widened tributary is quite complicated. However, despite the large variation in the bed morphology and the different specific flow discharges, the average flow field was shown by using the LSPIV technique. Moreover, the momentum flux ratio for this configuration was slightly higher than that for the reference configuration. The average surface flow velocity is presented in Fig. $6 \mathrm{~b}$ for the reference configuration and in Fig. 6c for the widened configuration. The bed morphology was compared with the corresponding surface flow patterns to investigate the maximum scour zone. For both configurations, the high velocity zone occurs at the outer bank at the post-confluence channel. Flow from the main channel plunges to the bed at this point, and the surface flow is composed of water from the tributary. The tributary flow "pushes" the main flow to the outer bank of the confluence zone. This behaviour explains the fact that the maximum scour zone is located near the outer bank of the postconfluence channel. The maximum scour depth for the initial condition is located at cross section S4. This cross section corresponds to the extension of the inner corner of the confluence into the post-confluence channel. If the tributary is widened, the maximum erosion depth decreases but still occurs at the extension of the right corner of the tributary (cross-section S5; $x=4.1$ ). However, the erosion zone is larger for the widened configuration.

\subsection{Application in dam engineering and the spillway of hydropower plants}

Physical modelling in dam engineering was used to study the influence of hydraulic structures, such as water intakes and spillways, on the flow field. LSPIV enables the analysis of several aspects of the flow structure interaction by the definition of surface flows. By studying water intakes, stagnant and upstream flows and vortices could be detected and qualified. In this case, the absence of surface outflow limited the test duration due to the accumulation of seeding. LSPIV tests are especially useful in the assessment of free surface spillways in reservoirs. The knowledge of surface flow patterns allows the evaluation of accelerated flow fields, circulation cells, zones of upcoming sub-surface flows, surface flow separation, and possible risks of cavitations and logjams.

\subsection{Dam case 1: Approach flow in the reservoir of the Shahryar dam in Iran}

The Shahryar Dam is currently under construction on the Qezel Owzan River (East Azerbaijan Province) in northwest Iran (Martinerie et al., 2007). It consists of a double-curvature arch dam with a height of $135 \mathrm{~m}$ and a crest length of $204 \mathrm{~m}$. High flood discharges expected from the river are important, with $\mathrm{Q}_{1000}$ estimated at $5130 \mathrm{~m}^{3} / \mathrm{s}, \mathrm{Q}_{10,000}$ at $8400 \mathrm{~m}^{3} / \mathrm{s}$ and the probable maximum flood (PMF) at $14570 \mathrm{~m}^{3} / \mathrm{s}$. To evacuate the discharges, two spillways were designed: a free crest spillway in the centre of the dam following the curvature of the dam body and a gated spillway located on the right bank preceded by an approach channel and equipped with three chutes and flip buckets (Fig. 7a). The upstream velocity field was measured using LSPIV for high return period floods $\left(\mathrm{Q}_{10,000}\right.$ and $\left.\mathrm{PMF}\right)$. When applied to the physical model, this measurement technique can highlight the general surface flow from the model's discharge supply (two perforated pipes separated from the reservoir with a permeable curtain for flow distribution) to the spillways.

Fig. $7 \mathrm{~b}$ presents the results of upstream surface velocity measurements for $\mathrm{Q}_{10,000}$. For high return period floods with a discharge higher than $5000 \mathrm{~m}^{3} / \mathrm{s}$, the three gates of the spillways are fully opened, and the bays evacuate a significant part of the total discharge, representing $86 \%$ for $\mathrm{Q}_{1000}, 70 \%$ for $\mathrm{Q}_{10,000}$ and $58 \%$ for PMF. The gated spillway is directed at $45^{\circ}$ from the axis of the valley, which leads to a small approach area and imposes high velocities to reach the weir with streamlines oriented on the axis of the spillway. Finally, the flow has to be redirected to the axis of the spillway, which involves an important turn around the left guide wall and a consecutive flow contraction.
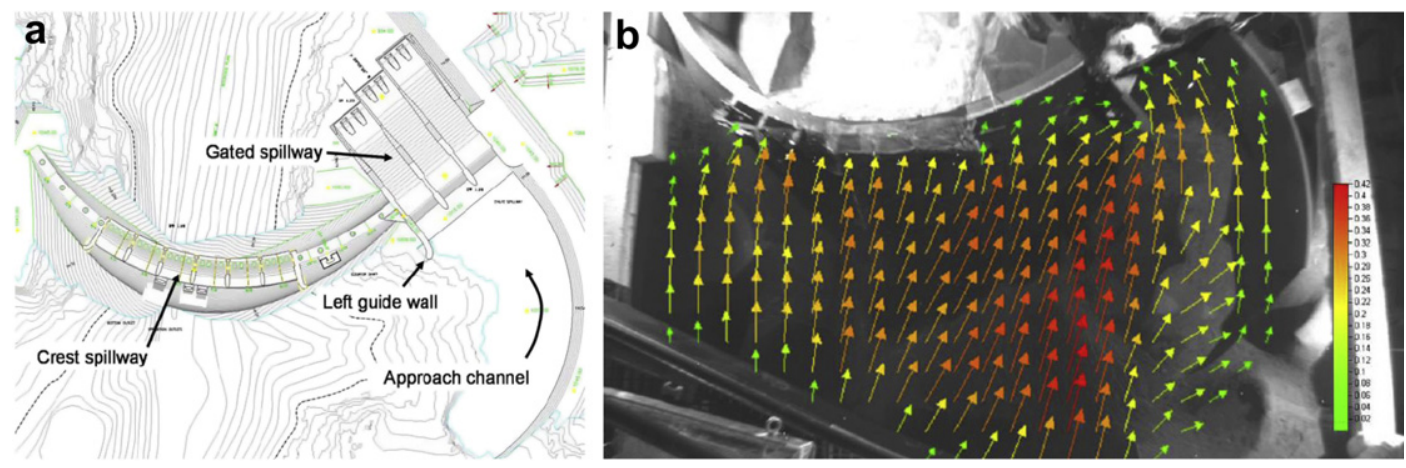

Fig. 7. (a) Layout of works of Shahryar dam model built at LCH (Martinerie et al., 2007) (b) LSPIV upstream velocity field for $\mathrm{Q}_{10,000 .}$ 


\subsection{Dam case 2: Teesta VI hydropower plant in Sikkim state, Northern India}

The 500 MW Teesta VI hydropower project, located on the Teesta River in southern Sikkim, India, is a run-of-river scheme. Hydraulic model tests were conducted at the Laboratory of Hydraulic Constructions ( $\mathrm{LCH})$ of the Ecole Polytechnique Fédérale de Lausanne (EPFL) (De Cesare et al., 2010). The model includes a part of the upstream river section, the barrage with the four spillway passages, the river intakes and the four desander basins, two power intakes, and a part of the downstream river (Fig. 8a). The main purpose of the hydraulic model tests was to assess the viability of the arrangement of the barrage, desanders and power intake.

During high monsoon floods, the river bed load and suspended sediment will be diverted through the spillway openings placed at riverbed level. To reduce the erosion wear at the guide vanes and runners of the turbines, desanding basins have to be provided. They were designed and dimensioned based on the principal that a reduction of the water velocity helps sediment particles to settle down. In this paper, special attention is given to the river intake design (i.e., orientation and form) and the desander basin size. The flow conditions were assessed using LSPIV and ultrasonic Doppler velocity profiler (UVP) measurements, as shown in Fig. 9.

The river intake is the most upstream element for run-ofriver hydropower production. Its objective is for the powerhouse design discharge, regardless of river discharge, to ensure uniform water deviation throughout the width and water depth, to keep the entrance free from bed load and floating debris, and to present a homogeneous flow velocity at the trash rack section. Large eddies in the river approach zone should be prevented from entering the desanders, and swirling flow at piers and an upstream dead zone should not occur during normal flow conditions. The flow inside the desander should be as homogeneous as possible to allow an efficient sediment settling process. For general design criteria and example details of desilting chambers, see Ortmanns and Minor (2007). The discharge was fixed at half the powerhouse design discharge $\left(531 \mathrm{~m}^{3} / \mathrm{s}\right)$ per power intake and pair of desanders.

Fig. 8b shows the surface velocity field for the upstream river section, water intake and desander basins for regular operation (design discharge and normal water level).

\subsubsection{Accuracy of LSPIV measurements and comparison with concurrent UVP data}

The velocity profiles in the water column at the entrance, middle, and outlet sections of the desanders were measured by means of a UVP, which allows the instantaneous measurement of the 1D velocity profile over the entire flow depth, as shown in Fig. 9. The measurement probe was fixed on a support, inclined at $30^{\circ}$ to the vertical and had an emitting frequency of $2 \mathrm{MHz}$. For each desander, two cross sections with three points each were measured to investigate the flow rate for each desander. The UVP measurements were used as a reference for LSPIV measurements. Vertical velocity profiles at desander 2 (in the left, middle, and right) show that the LSPIV measurements at the left and middle locations are approximately the same as the sub-surface velocities measured by UVP. However, at the right location, the LSPIV surface velocity is less than the sub-surface velocity measured by UVP. A comparison of the measured velocity by UVP and LSPIV suggests that measurements with the two techniques are in good agreement, as shown in Fig. 9.

\subsection{Dam case 3: Les Gloriettes dam, PKW, France}

The right part of the arch dam with the existing spillway and the right bank near the dam were modelled in the experimental tank with dimensions of $4 \mathrm{~m} \times 4 \mathrm{~m} \times 1 \mathrm{~m}$. The water enters on the opposite side. A differently perforated tube allows a well distributed water supply. After a permeable brick-lined wall and a flow stabiliser screen distributed the water homogenously, a rotary seeding supply system allowed a continuous feeding during the tests. The zenithally-fixed camera covered the entire width of the downstream part of the tank. The LSPIV measurements were performed for $1 \mathrm{~min}$, and the results were compared to Micro-Propeller and UVP measurements, as a

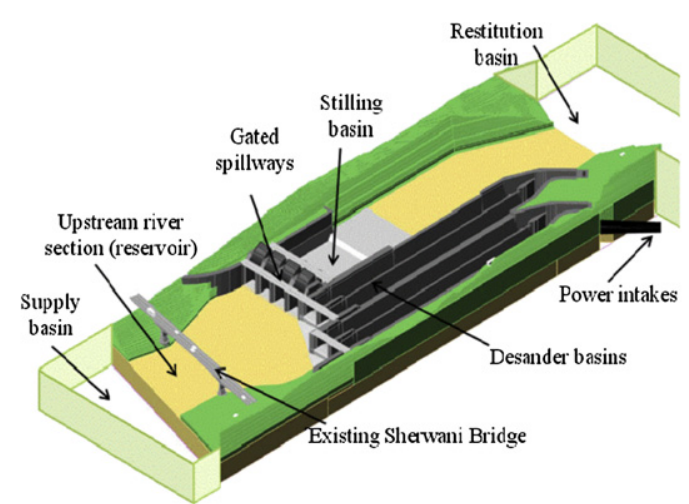

b

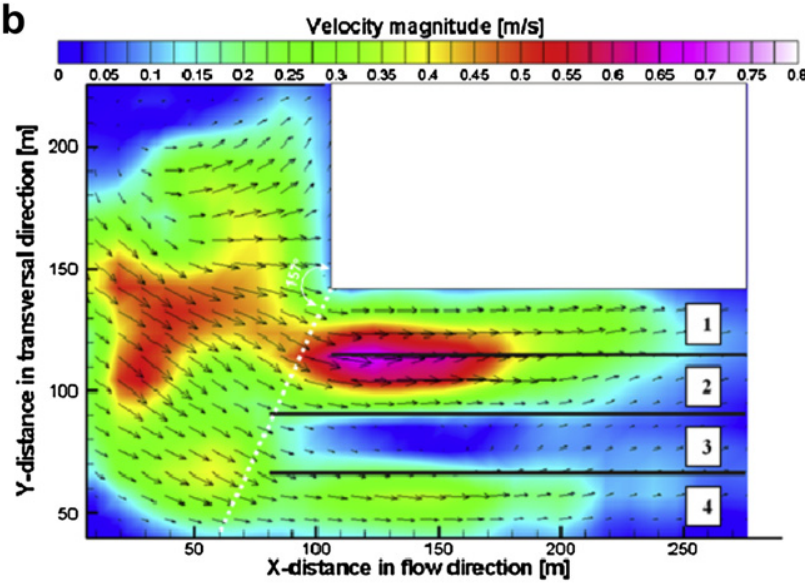

Fig. 8. (a) Boundaries and components of the physical model in its original river intake configuration (De Cesare et al., 2010); (b) Average flow pattern with surface velocity vectors by LSPIV for the initial intake design $\left(Q=531 \mathrm{~m}^{3} / \mathrm{s}\right.$, water level $360 \mathrm{~m}$ a.s.l.). 

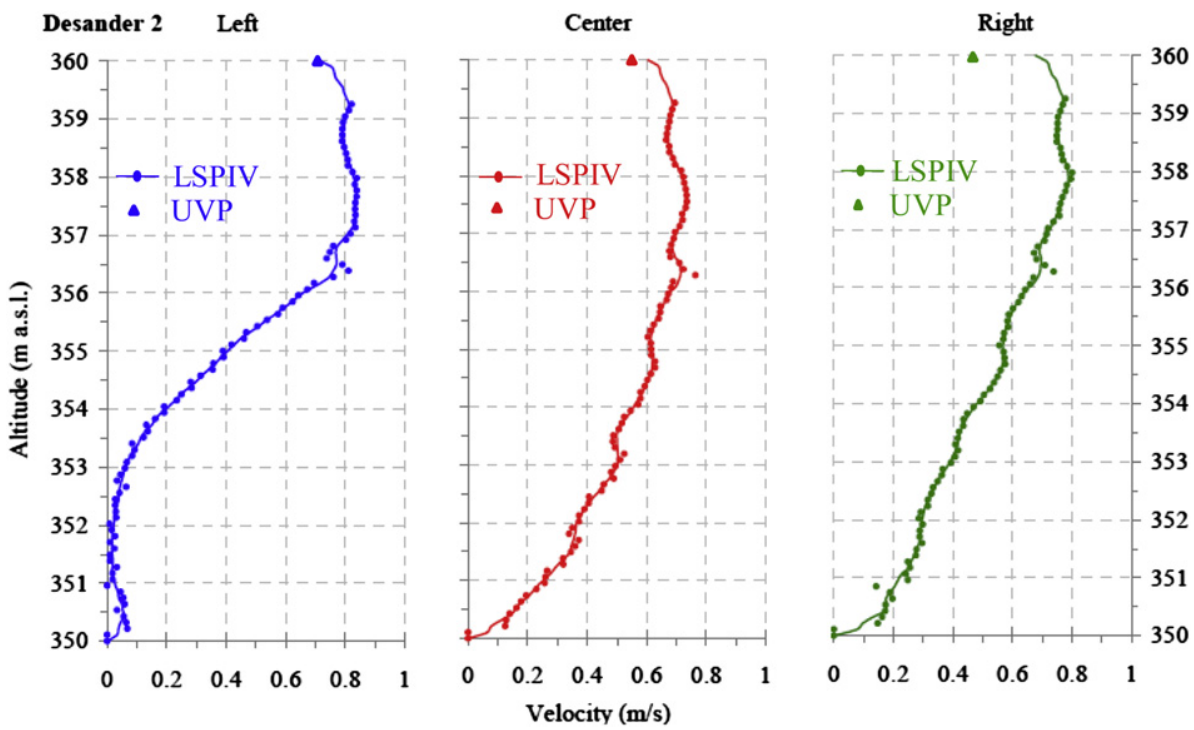

Fig. 9. LSPIV-UVP data comparison: velocity at the free surface (LSPIV) and vertical velocity distribution by UVP at the entrance of desander $2 ; Q=531 \mathrm{~m}^{3} / \mathrm{s}$; $\mathrm{WL}=360 \mathrm{~m}$ a.s.l.

shown in Fig. 10. The LSPIV results were first compared with the velocities measured by UVP at position cross-section C. UVP measurements were conducted to measure vertical velocity profiles every $50 \mathrm{~cm}$ in the model at eight lateral locations for the configuration of the extended spillway and flood design of $150 \mathrm{~m}^{3} / \mathrm{s}$, as shown in Fig. 10. Moreover, at the same locations of UVP measurements, a micro-propeller was used to validate both UVP and LSPIV data (Fig. 10). Fig. 10 shows that the surface velocities measured with LSPIV coincide well with the surface velocities measured by both other techniques, except for the flood design of $150 \mathrm{~m}^{3} / \mathrm{s}$, which confirms that the velocities of the water surface can be measured and predicted reasonably well with LSPIV.

The present configuration generally shows high surface velocities of about $0.5 \mathrm{~m} / \mathrm{s}$ (see Fig. 11 top. The existing spillway is principally supplied from the left of the reservoir.

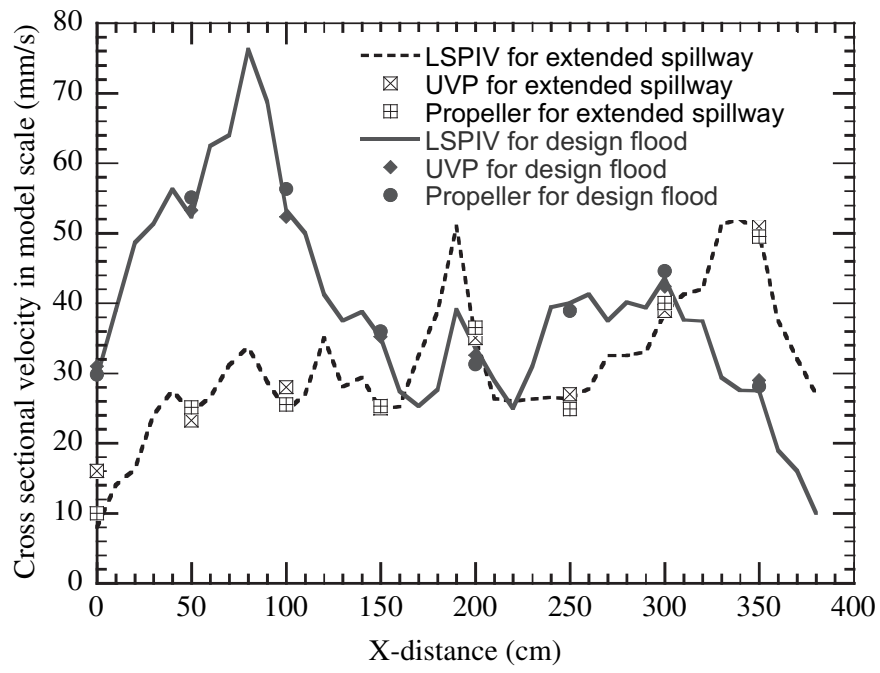

Fig. 10. Cross section velocity profiles comparison obtained from LSPIV, UVP, and micro-propeller for extended spillway and for the design flood of $150 \mathrm{~m}^{3} / \mathrm{s}$
In the right and central part of the basin, surface velocities are reduced, which indicates the presence of sub-surface upstream flows near the dam close to the two sluices on the left. The two sluices on the right create an accelerated flow field, which means that they are more surface-supplied than the sluices on the left. The implementation of the PKW (see Fig. 11 below) leads to a reduction of the surface flow velocities. Approximately $60 \%$ of the reservoir width supplies the three existing sluices. The sluice on the right evacuates the water from sub-
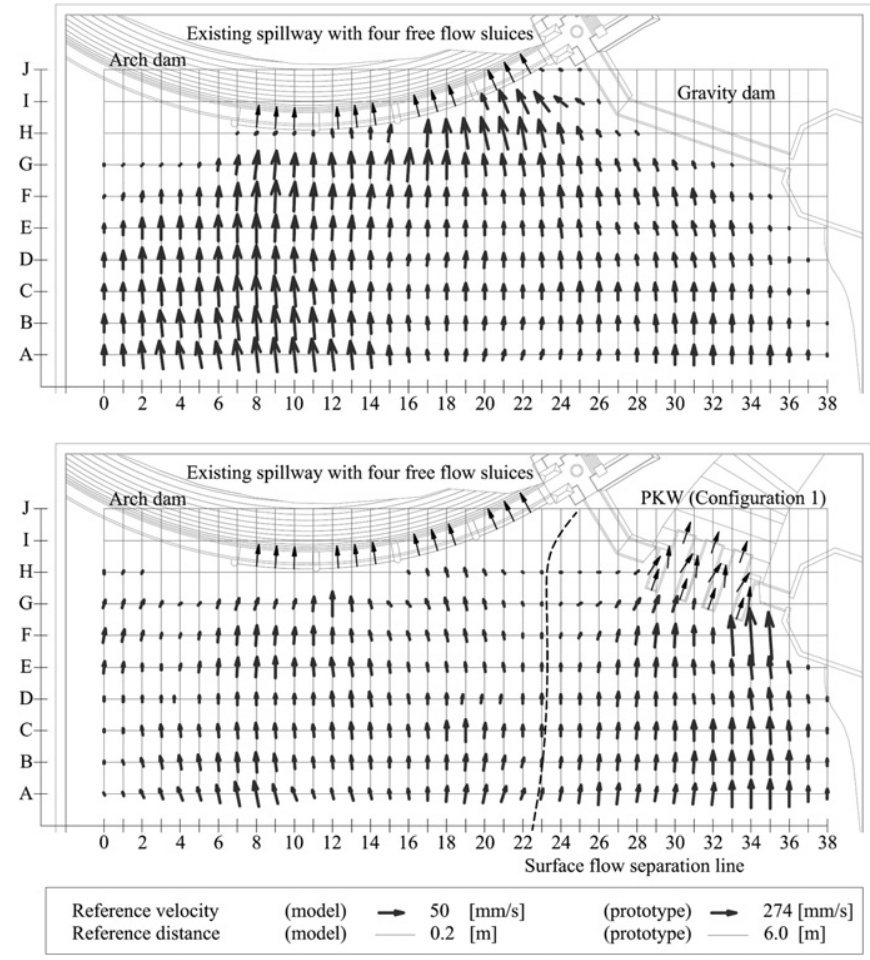

Fig. 11. Stationary flow fields for the initial (above) and the extended spillway (below) for the design flood of $150 \mathrm{~m}^{3} / \mathrm{s}$. 
surface flows near the dam abutment (position 23-I). The indicated surface flow separation line reveals the independent operating mode of the two spillways and confirms the efficiency of the hydraulic design.

\subsubsection{Seeding particles}

The total error in PIV data is a function of out-of-plane particle motion, the particle size, the particle density, the peak locking, the dynamic range of measured pixel displacements and the sub-pixel interpolation scheme employed. Seeding density impacts data quality and must be sufficiently high so that an adequate number of seeding particles (two or more) are within the interrogation area between frames and sufficiently low that pronounced particle agglomeration does not cause saturation of the interrogation area, which leads to measurement error. Thus, data points were removed if agglomeration or inadequate tracer particles occurred in the image area. Tests in which the particle concentration was changed showed that the number of particles in each interrogation area should be greater than five. The dispenser operation for all laboratory models satisfies this criterion.

\subsection{Application in coastal engineering: LSPIV in the vicinity of an oil spill barrier}

Oil spills represent major environmental concerns in coastal regions and in rivers. Oil containment barriers are known to be the most effective tool to prevent the spread of spilled oil over water surfaces in open seas or to divert the spilled oil in the case of an oil spill incident in rivers. The main aim of the present research project was to investigate the efficiency limits of a containment system. To assess the behaviour of a containment system, it was of crucial importance to evaluate the velocity field in the vicinity of the barrier. For this purpose, experiments were conducted in a 6.5 -m-long, 1.2-m-high, and 12-cm-wide laboratory flume (Amini, 2007). The velocity field was measured using the non-intrusive method of LSPIV. The PIV measurements were previously used by Chang and Liu (1998) to investigate the velocity and vorticity under a breaking wave and by Lee et al. (2004) to study the flow characteristics between tandem booms. A digital video camera (SMX-150, monochrome, 1.2 megapixels), connected to a computer, was used to record images. It was fixed perpendicular to the flume wall at a distance of $2.2 \mathrm{~m}$ from the wall and covered an area of $0.875 \mathrm{~m}$ by $1.17 \mathrm{~m}$.

During the experiments, seeding was provided by a distributer, located upstream of the barrier. To find an appropriate seeding particle, several particles were examined. A summary of their properties is presented in Amini et al. (2008). The LSPIV accuracy depends on the ability of the particles to follow the flow fluctuations. When a particle is placed inside the flow or when the flow has a velocity oscillation, a time lag is required until the particle velocity is equal to the flow velocity. Therefore, the fluid mechanical properties of the particles have to be checked to avoid large discrepancies between fluid and particle motion. The ability of the tracer to follow the flow streamlines was evaluated by determining the settling velocity of the particle under gravity. A summary of the properties of the tested tracer particles is presented in Table 2.

The best seeding was found to result from the Grilon AZ 3 (EMS-Chemie, Switzerland) polymer particles. The particles had an average diameter of $2.4 \mathrm{~mm}$ and a density of $1.07 \mathrm{gr} /$ $\mathrm{cm}^{3}$. Hollow, cylindrical particles allowed the water to pass through them and keep them moving with the same velocity as the water. To illuminate the measuring area, three external lights and one neon light at the bottom of the flume were used. The back wall of the flume was painted with a black colour to provide an adequate contrast with the white particles and to improve the images.

Measurements were conducted for rigid and flexible barriers with $10-$ and $20-\mathrm{cm}$ drafts at a mean flow velocity of $20 \pm \mathrm{cm} / \mathrm{s}$.

Fig. 12 illustrates the velocity field and vectors for flow passing a rigid barrier with a $20-\mathrm{cm}$ draft. Before analysing the results, the laboratory effects should be considered. In the bottom left area of the observing window, there was a lack of appropriate illumination, and a shadow zone could thus be observed in the results at this area (Fig. 12 (region a)). The presence of the barrier caused some tracer particles to accumulate behind it (Fig. 12 (region b)) and to prevent them from following the flow. As a result, the obtained velocity for that region is underestimated. Despite the aforementioned problems and shortcomings, LSPIV measurements provided interesting results regarding the velocity field and streamlines in the vicinity of the barrier.

As shown in Fig. 12 (region c), the flow accelerated beneath the barrier. For the rigid barrier with a $10-\mathrm{cm}$ draft, the influenced water depth was about seven times the barrier draft. The maximum velocity measured beneath the barrier (Fig. 12 (region c)) had a higher velocity in the case of a rigid barrier compared to a flexible barrier. The turbulence wake downstream of the barrier was partially captured. The wake was deeper for rigid compared to flexible barriers (Fig. 12 (region d)).

\subsubsection{LSPIV sensitivity to turbulence}

As in traditional PIV, image quality is a key issue in LSPIV. The image scale and resolution are determined by the nature of the CCD sensor in the PIV camera and by the lens employed, and they vary with the scale of the flow under study. The instantaneous vector maps and the large number of instantaneous vector maps were used to calculate the mean velocity and turbulence quantities; the uncertainties in the mean velocity at the $95 \%$ confidence level were estimated to be $2 \%$ of the local value, while those in the mean momentum flux and

Table 2

Main properties of examined seeding particles for LSPIV measurements.

\begin{tabular}{llll}
\hline $\begin{array}{l}\text { Polymer } \\
\text { material }\end{array}$ & Color & $\begin{array}{l}\text { Density } \\
{\left[\mathrm{gr} / \mathrm{cm}^{3}\right]}\end{array}$ & $\begin{array}{l}\text { Diameter } \\
{[\mathrm{mm}]}\end{array}$ \\
\hline Griliamid L16-LM & Semi-transparent white & 1.01 & 2.6 \\
Grilon TSS/4 & Semi-transparent white & 1.13 & 2.7 \\
Grilon Az 3 & Opaque white & 1.07 & 2.4 \\
\hline
\end{tabular}




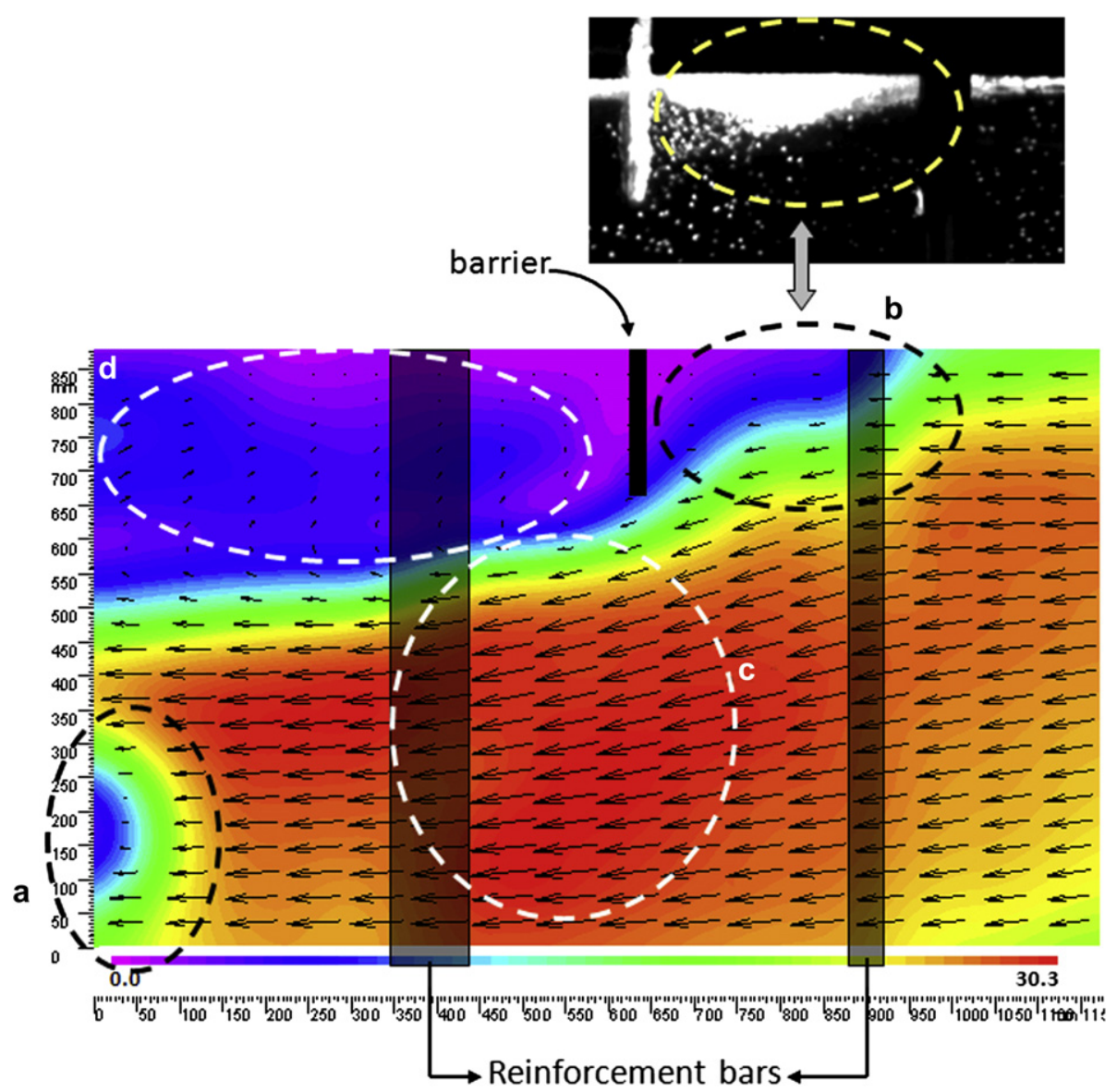

Fig. 12. Contours of velocity magnitude and velocity vectors derived from LSPIV measurements in the vicinity of a barrier with $20 \mathrm{~cm}$ draft and mean flow velocity of $20 \mathrm{~cm} / \mathrm{s}$; dark bands show the location of reinforcement bars of the laboratory flume; velocity magnitude is presented in $\mathrm{cm} / \mathrm{s}$.

vorticity were 5\%. Averaging was done over 1000 PIV images. Therefore, the LSPIV method is appropriate for measuring other statistics as shown by Kantoush and Schleiss (2009a).

\section{Field case}

\subsection{LSPIV equipment}

In the field application case, the monitoring video camera CCTV (CIT-7300) from Mitsubishi Electric Corporation was used. The camera was connected to a computer to record the movie data directly. The flow videos were recorded at $30 \mathrm{fps}$ and 740 by 480 pixels. Naturally occurring turbulence, sediment clouds, differences in water colour, bed features, and reflections on the flow surface were used as seeding tracers. The combination of these tracers was present during floods or flushing in the reservoir, which supports the LSPIV measurements in a situation where none of the other techniques can be used due to safety. Distortion correction was not necessary because image deformation was negligible. All of the other steps of the LSPIV processing as before were in place for the field case study. The image processing was performed using 32 by 32 pixel interrogation areas following the cross-correlation algorithm used in the FlowManager software. Based on the accurate dimensions and coordinates of targets placed on the concrete structure of the Unazuki Dam, the image pixel size was converted to a metric size $(1$ pixel $=60 \mathrm{~mm}$ ). LSPIV measurements produced instantaneous velocity vector fields covering the imaged area. By averaging these vector fields over a 1-s time interval, the mean velocity at a specific zone was compared with the results obtained by the FX-8100 from the Mitsubishi Electric Corporation. The image quality was not always favourable for surface flow measurements because, in some cases, raindrops and snow hit the surface and caused a screen effect that blocked the sight, and in other cases, either the illumination was not sufficient for visualisation of the surface image or there was too much sunshine, which caused too much light and too many reflections. Moreover, wind and fog created another severe curtain that blocked the target area. Such image deterioration makes it difficult to apply LSPIV directly to these images. In such cases, artificial illumination and seeding was required for LSPIV to measure the surface velocity reliably.

\subsubsection{Optical flow by $F X-8100$}

The optical flow technique has been widely used for measurements and visualisation in the field of machines. Optical flow computation consists of tracking a dense velocity field from an image sequence by assuming that the intensity is conserved during the displacement. FX-8100, which is a video 

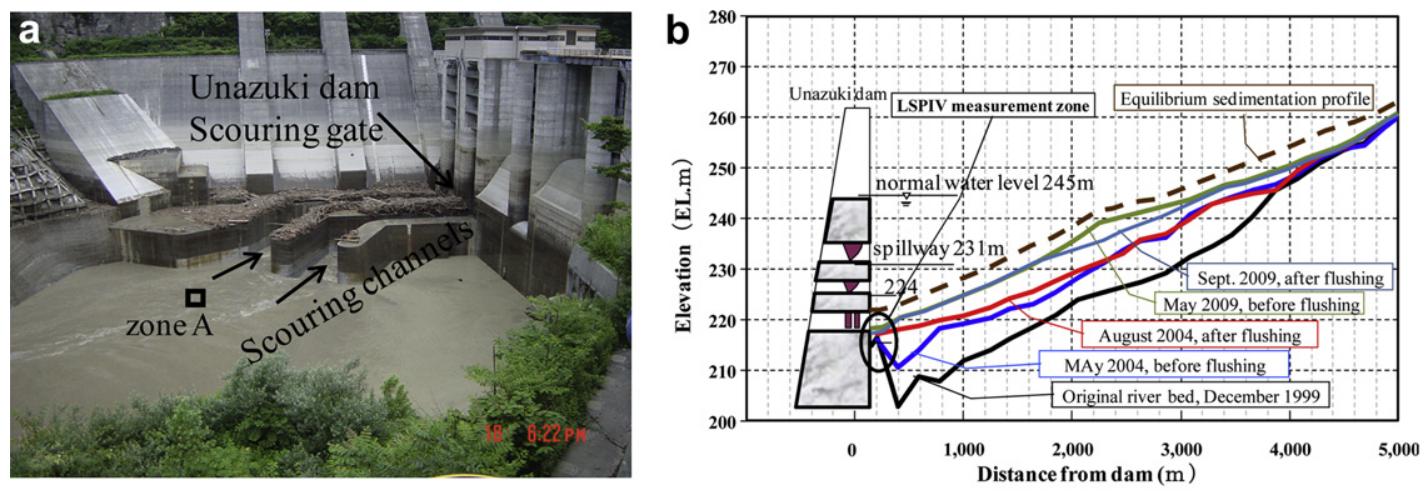

Fig. 13. During drawdown flushing in Unazuki reservoir (a) Location of surface velocity measured by LSPIV and FX-8100 in front of scouring channels (zone area A); (b) Actual field longitudinal bed profiles variations in time along Unazuki reservoir and LSPIV measurement zone.

front end processor (FEP) and a multipurpose image recognition platform, was developed by the Mitsubishi Electric Corporation. It is a platform designed to recognise the video image, and it has many image processing functions, logic and a network interface. The functions of a FEP can be enhanced by updating the program according to different applications. LSPIV and FX-8100 techniques were applied for the sediment bypass tunnel of Miwa Dam (Kantoush et al., 2011). The average estimated accuracy of FX-8100 is $6 \%$ based on the study by Sumi et al. (2006).

\subsection{Application to the Unazuki Reservoir: LSPIV during sediment flushing}

\subsubsection{Purpose of the study}

Flushing is vital for the preservation of long-term storage in reservoirs. However, downstream impacts such as turbidity act as a constraint in the planning and operation of sediment flushing. The main objective of the field measurement was to predict the amount of suspended sediment concentrations and to evaluate the effects of sediment flushing in the Kurobe River. Moreover, from the point of view of environmental assessment of the flushing operation, how and when high sediment concentration discharge from reservoirs will occur is one of the key issues.

\subsubsection{Measurement methods}

To understand the processes and the impacts of flushing (how and when high sediment concentration will occur), LSPIV and FX-8100 were implemented in the study of the Unazuki Reservoir, which is located in the Kurobe River in the eastern region of the Toyama Prefecture, Japan. Field measurements were achieved during sediment flushing in July 2006. The time and spatial variations of the reservoir surface velocities during the drawdown period were measured by LSPIV and FX-8100.

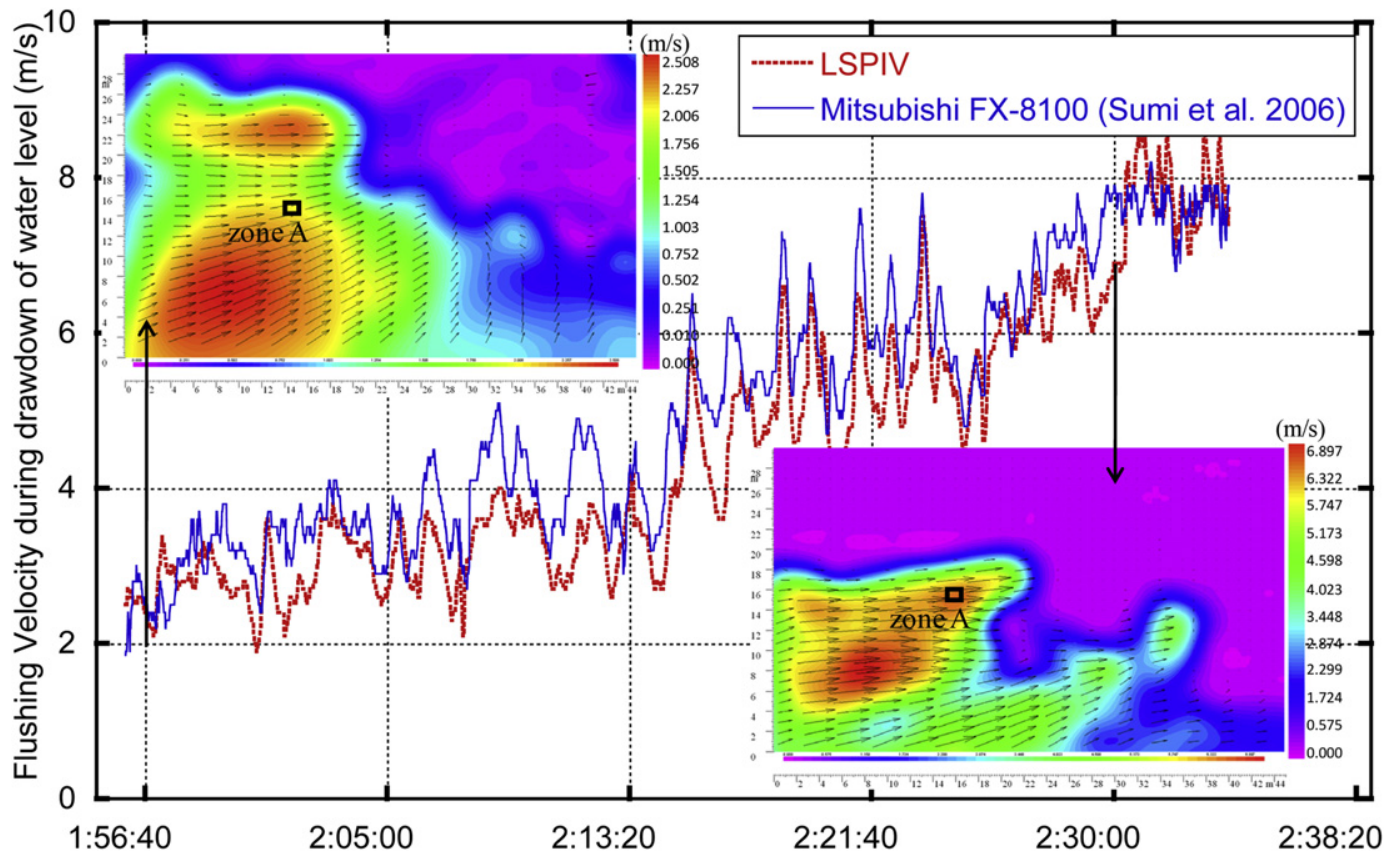

Fig. 14. Average velocity every second at zone A and flow patterns in the Unazuki reservoir at $1 \mathrm{~h} 56$ and $2 \mathrm{~h} 30$ treated by LSPIV. 


\subsubsection{Results}

The upstream side of the Unazuki Dam and the inlet of two sediment scouring gates during drawdown flushing are shown in Fig. 13a. The sediment scouring channels were both equipped with flushing gates with dimensions of $5.0 \mathrm{~m} \times 6.0 \mathrm{~m}$. The three gates at the upstream, intermediate, and downstream sides are high-pressure slide gates (Fig. 13b). The purposes of flushing facilities are to sustain the original functions of the dam and maintain the sediment routing system within the reservoir. The previous and present longitudinal sediment profiles of the Unazuki Dam are shown in Fig. 13b. The reservoir areas in front of the scouring channels were monitored by a camera that was located on the bridge, and the region recorded by LSPIV is shown in Fig. 13b. To compare and validate the capabilities of LSPIV, a small area A of $40 \times 50$ pixels (Fig. 13a) in front of the scour channel was measured by FX-8100. The flow discharged during $17 \mathrm{~h}$, and then the erosion phase in a free flow state continued for $12 \mathrm{~h}$ to flush out a sediment volume of $240,000 \mathrm{~m}^{3}$. The total drawdown flushing period at the Unazuki Dam was $60 \mathrm{~h}$.

To compare and validate LSPIV, a small area A of 40 by 50 pixels (Fig. 14) was measured by FX-8100 as well. Images used for video analysis were recorded at $1 \mathrm{~h} 50$ to $2 \mathrm{~h} 40$, and the results of the averaged velocity of $1 \mathrm{~min}$ at zone A are shown in Fig. 14. Both techniques were able to monitor the behaviour of the average surface velocity during flushing. The flow had a periodic fluctuation approximately every $1 \mathrm{~min}$ during acceleration. This tendency is shown in Fig. 14. Due to the decrease of the water surface level, the amount of the reservoir surface area covered with water was reduced. Fig. 14 shows the comparison between the LSPIV and FX-8100 data at zone A. Two examples of the LSPIV flow field and velocity magnitudes at $1 \mathrm{~h} 56$ and $2 \mathrm{~h} 30$ are shown in Fig. 14. The surface velocities within the reservoir during drawdown flushing measured by LSPIV agreed reasonably well with those measured by FX-8100.

\section{Conclusions}

The potential of LSPIV to measure the surface flow velocities in the context of river, dam, coastal and reservoir engineering projects was shown in this paper. The LSPIV method was shown to take into account the specific constraints of high flow conditions created by each application separately. LSPIV velocity measurements can help to analyse and optimise flow pattern conditions. The LSPIV method was successfully implemented to obtain velocity measurements despite water surface elevation variations, variations in light intensity, stationary waves and rains. LSPIV measurements at the water surface, using an appropriate camera and natural or artificial seeding tracers, provide a suitable method for analysing the surface flows influenced by different hydraulic structures. The technique described can be used in any other application where the surface velocities completely or partially explain the behaviour of the overall flow, such as shallow wake flows or confluence problems in rivers. The next challenge is how to apply LSPIV in more severe weather conditions.

\section{References}

Admiraal, D., Stansbury, J., Haberman, C., 2004. Case study: particle velocimetry in a model of Lake Ogallala. Journal of Hydraulic Engineering 130 (7), 599-607.

Amini, A., 2007. Contractile floating barriers for confinement and recuperation of oil slicks, thesis No. 3941, EPFL and Communication No. 35 of LCH.

Amini, A., Kantoush, S.A., Schleiss, A.J., 2008. Velocity Field Measurements in the Vicinity of an Oil Spill Barrier Using LSPIV Method. Proc. of the International Conference on Fluvial Hydraulics. IAHR. Izmir, Turkey, September 3-5, 2008.

Aya, S., Fujita, I., Yagyu, M., 1995. Field-observation of flood in a river by video image analysis. Annual Journal of Hydraulic Engineering 39, 447-452 (in Japanese).

Bieri, M., Jenzer, J., Kantoush, S.A., Boillat, J.-L., 2009. Large Scale Particle Image Velocimetry Applications for Complex free Surface Flows in River and Dam Engineering. 33rd IAHR Congress Proc. British Columbia, Vancouver. 604-611.

Chang, K.A., Liu, P.L.F., 1998. Velocity acceleration and vorticity under a breaking wave. Physics of Fluids 10 (1), 327-329.

Creutin, J.D., Muste, M., Bradley, A.A., Kim, S.C., Kruger, A., 2003. River gauging using PIV technique: proof of concept experiment on the Iowa River. Journal of Hydrology 277, 182-194.

De Cesare, G., Ribeiro, J.M., Kantoush, S.A., Federspiel, M.P.E.A., 2010. River Intake and Desander Efficiency Testing on a Physical Model using UVP and LSPIV, Proc. of 7th ISUD, Gothenburg, pp. 47-50.

Ettema, R., Fujita, I., Muste, M., Kruger, A., 1997. Particle-image velocimetry for whole-field measurement of ice velocities. Cold Regions Science and Technology 26 (2), 97-112.

Fujita, I., Komura, S., 1994. Application of video image analysis for measurements of river surface flows, Proc. of hydraulic engineering. JSCE 38, 733-738 (in Japanese).

Fujita, I., Muste, M., Kruger, A., 1998. Large-scale particle image velocimetry for flow analysis in hydraulic engineering applications. Journal of Hydraulic Research 36 (3), 397-414.

Fujita, I., Aya, S., 2000. Refinement of LSPIV Technique for Monitoring river Surface Flows Proc. of Water Resource Engineering, Planning and Management, Minneapolis, USA.

Fujita, I., Tsubaki, R., 2002. A Novel free-Surface Velocity Measurement Method using Spatio-Temporal Images Proc. of Hydraulic Measurements and Experimental Methods, ASCE-IAHR Conference, Estes Park, USA.

Jodeau, M., Hauet, A., Paquier, A., Le Coz, J., Dramais, G., 2008. Application and evaluation of LS-PIV technique for the monitoring of river surface velocities in high flow conditions. Flow Measurement and Instrumentation 19, 117-127.

Kantoush, S.A., De Cesare, G., Boillat, J.-L., Schleiss, A.J., 2008. Flow field investigation in a rectangular shallow reservoir using UVP, LSPIV and numerical modelling. Journal of Flow Measurement and Instrumentation 19 (3-4), 139-144.

Kantoush, S.A., Schleiss, A.J., 2009a. Large scale PIV- measurements at the surface of different shallow reservoir geometries. Journal of Visualization 12 (4), 361-373.

Kantoush, S.A., Schleiss, A.J., 2009b. Channel formation in large shallow reservoirs with different geometries during flushing. Journal of Environmental Technology 30 (8), 855-863.

Kantoush, S.A., Sumi, T., 2010. The Impacts of Sediment Replenishment Below Dams on Flow Behaviour and Bed Morphology of River Channel and River Mouth. First International Conference, Coastal Zone management. River Deltas and Low Land Coastlines, Alexandria, Egypt.

Kantoush, S.A., Sumi, T., Murasaki, M., 2011. Evaluation of sediment bypass efficiency by flow field and sediment concentration monitoring techniques. JSCE 55, S169-S174.

Lee, C.M., Han, D.G., Kang, K.H., Lee, S.J., 2004. Investigation of the effectiveness of tandem oil fences under currents. Marine Science and Technology 8, 117-125.

Le Coz, J., Hauet, A., Pierrefeu, G., Dramais, G., Camenen, B., 2010. Performance of image-based velocimetry (LSPIV) applied to flash-flood discharge measurements in Mediterranean rivers. Journal of Hydrology. doi:10.1016/j.jhydrol.2010.05.049. 
Leite Ribeiro, M., Wampfler, S., Blanckaert, K., Schleiss, A., 2008. Influence of the Widening of a Tributary on Confluence Morphology: Preliminary Results, Proce. of the second international junior researcher and engineer workshop on hydraulic structures, pp. 195-202, Pisa, Italy.

Martinerie, R., Boillat, J.-L., Schleiss, A., Parvaresh Rizi, A., 2007. Experimental Study of the Gated Spillway of the Shahryar Dam in Iran Proc. 32nd Congress of IAHR, vol. C2.b-157-O.

Meselhe, E.A., Peeva, T., Muste, M., 2004. Large scale particle image velocimetry for low velocity and shallow water flows. Journal of Hydraulic Engineering 130 (Issue 9), 937-940.

Muste, M., Fujita, I., Hauet, A., 2008. Large-scale particle image velocimetry for measurements in riverine environments. Water Resources Research 44, 1-14. doi:10.1029/2008WR006950. W00D19.

Müller, G., Bruce, T., Kuppert, K., 2002. Particle Image Velocimetry: a Simple Technique for Complex Surface Flows Proc., River Flow, Louvain-laNeuve B, Lisse, 1227-1232.
Morales, R., Ettema, R., Barkdoll, B., 2008. Large-Scale flume tests of riprapapron performance at a bridge abutment on a floodplain. Journal of Hydraulic Engineering 134 (6), 800-809.

Ortmanns, C., Minor, H.-E., 2007. Flow and turbulence conditions on the design of desilting chambers. Dam Engineering 17/4, 257-269.

Sun, X., Shiono, K., Chandler, J.H., Rameshwaran, P., Sellin, R.H.J., Fujita, I., 2010. Proc. of the nstitution of civil engineers water management. Discharge Estimation in Small Irregular River Using LSPIV, vol. 163 (WM5), 247-254.

Sumi, T., Murasaki, M., Taira, K., Shinbo, K., Nagura, H., Tamaki, H., 2006. Study on measurement of fine sediment discharge process during sediment flushing operation using PIV. Annual Journal of Hydraulic Engineering, JSCE 51, 1075-1080.

Weitbrecht, V., Kühn, G., Jirka, G.H., 2002. Large scale PIV-measurements at the surface of shallow water flows. Flow Measurement and Instrumentation 13, 237-245. 